\title{
Conclusiones, complementos y nuevos debates
}

$\mathrm{E}$ cóndor y el águila no solo danzaron, también se mataron entre sí. Sin embargo, su muerte anunciaba la matanza, el exterminio, que provocaría la llegada del hombre blanco. Esto corrobora una explicación arquetípica y panindianista en la que los factores y las condiciones que afectaron estructuralmente las culturas nativas americanas suelen ser atribuidos a los procesos de conquista y colonización. Desde tal perspectiva, la hermandad y la unión caracterizaban la era precolombina y todos los males y enfermedades vinieron del otro lado del mar. Aun así, entre los muiscas de hoy también han emergido explicaciones sobre su sometimiento por parte de los europeos en las que su pueblo ya estaba dividido y las guerras y conflictos entre caciques, zipas y zaques fueron aprovechados por los mismos conquistadores para lograr su dominio y control. Algunos líderes muiscas encuentran en estas pugnas los orígenes de los conflictos actuales, y a medida que se apropian de un papel en esta narrativa, van creando anclajes.

Uno de los conflictos más representativos de la historia del pueblo muisca y que marcó claras diferencias políticas y territoriales encontradas por las tropas de Gonzalo Jiménez de Quesada fue entre el zipa Tisquesusa de Bacatá (Bogotá) y el zaque Quemuenchatocha de Chunza (Tunja) (Correa Rubio, 2004). De manera sarcástica varios opositores de la organización PNMC se refieren a los hermanos Niño Rocha, sus líderes, como el zipa y el zaque, ya que sus cabildos mayores coinciden con ambos territorios, por "creerse" autoridades indígenas y por los conflictos existentes entre ambas facciones. Algo similar escuché la noche en que presenté mis intenciones investigativas al taita Orlando Gaitán en su casa del barrio la Esmeralda en Bogotá, escuché de sus labios los conflictos históricos entre el zipa y el zaque para 
referirse a la manera como en cada comunidad muisca había personas disputándose el liderazgo espiritual y la forma como debía asumirse el llamado "despertar muisca”. Así nombró a las facciones de Ráquira, Cota, Sesquilé y reiteró las de PNMC. Era una radiografía del conflicto muisca en el que él había asumido un papel de mediador gracias a su experiencia en este campo.

Rodrigo, Xieguazinsa, de PNMC en Boyacá me contó que en una de las reuniones que hubo en el año 2009 para discutir los conflictos entre su organización y los cabildos oficiales, un joven de Ráquira recordaba la historia de los zipas y los zaques para reclamar que de ninguna manera se podía esperar que hoy se quisiera considerar al pueblo muisca homogéneo. Este fue precisamente el punto de partida de esta investigación. De ahí que me haya propuesto comprender y caracterizar el proyecto etnopolítico muisca a partir de sus diferencias, conflictos y heterodoxia.

A lo largo de los capítulos se ha argumentado que el proyecto etnopolítico no corresponde necesariamente a la existencia de un proyecto colectivo como fruto de un gran consenso, sino más bien a una red de conformación permanente de grupos y facciones. Dicho tejido sustenta una serie de conflictos que lejos de negar la existencia de la reetnicidad muisca, la afirman, la sustentan, la transforman continuamente y la reproducen de manera creativa. Partir de los diversos conflictos que componen un proyecto etnopolítico también nos permite comprender las identidades y las memorias indígenas como campos de diferencias y disputas que llegan a ser altamente reflexivos. Por esta razón, el trabajo de campo y la observación participante empleada en este no caracterizó a una población específica que ha logrado asumir naturalmente su etnicidad, por el contrario, ha consistido en identificar una red compleja de personas y grupos que la han debatido, reflexionado en profundidad e incorporado de diferentes maneras y en diferentes momentos.

Como resultado, los diferentes procesos étnicos en cada comunidad muisca han dejado un cuerpo de órdenes morales que en conjunto han conformado unos principios desde los cuales se perciben los papeles y las acciones de cada integrante. Tal cuerpo ha sido identificado gracias al registro de formas discursivas y narrativas, también 
altamente reflexivas, que son producidas, puestas en circulación y recibidas constantemente como un mercado del lenguaje. Insistí en que los conflictos, lejos de bloquearlo, demuestran la atmósfera emotiva, estética y política de un proyecto que se ha identificado como el "despertar muisca". A la larga, todo boom trae sus debates y luchas por la representatividad y la legitimidad de los procesos. Revisemos a continuación cómo fue nuestro recorrido.

\section{Las comunidades muiscas como fruto de tensiones transformadoras}

Las divisiones entre los llamados "cabildos urbanos y rurales" nos permiten inferir que mientras unos ven en las transformaciones y los tránsitos a la vida moderna la explicación del fin de las comunidades muiscas, otros, en cambio, las identifican como el telón de fondo de una resistencia gallarda, de una perdurabilidad pasiva y en silencio y como un coherente elemento dramático de las narrativas proféticas del “despertar". Para Heseen Yopasá, joven de la comunidad muisca de Suba, la supervivencia del muisca, que para él es un hecho indudable, se fundamenta en la capacidad adaptativa que este ha tenido y que hoy continúa demostrando. Llega a comparar las tensiones del presente y pasado indígenas con las de los samurai en Japón.

[...] para nosotros poder sobrevivir nos toca adaptarnos y seguirnos acoplando y adaptándonos para no desaparecer. Como yo le decía a algunos: "A la japonesa", porque los japoneses hicieron estrategias para mantener su cultura, adaptaron todo lo de Occidente a la cultura de ellos y, o sea, suena curioso, como un amigo del Amazonas que los admiraba mucho porque el samurai no había desaparecido y la filosofía de los samurai se mantiene, pero vestidos de paño con su maletín, su catana es el maletín, se va ha hacer negocios y esa es la nueva guerra de ellos, pero mantienen su filosofía, su quimono y sus vainas raras y ahora es uno de los países más ricos y avanzados del mundo. En cierto modo tomamos algo de eso, en cierto modo la única forma de sobrevivir es adaptándonos, tomando unos elementos de Occidente y hay muchas 
críticas pero a nosotros nos vale, porque para nosotros es poder mantener y sobrevivir. (Hessen Yopasá, 6 de noviembre del 2011)

Los procesos de adaptación y supervivencia son los factores de conflictos entre dos formas de comprender a las comunidades muiscas actuales. Por un lado, podrían ser identificadas -o idealizadas por muchos- como grupos corporativos cerrados y con un alto grado de solidaridad que luchan contra las fuerzas externas que los amenazan. Por otro, pueden ser leídas como comunidades con varios poderes y disputas internas motivadas por ambiciones personales y egocéntricas que pueden terminar fragmentando lo corporativo. Por lo tanto, una de las premisas de la presente investigación fue que en el marco de los estudios de conflictos étnicos es sano, por cuestiones analíticas, sospechar del carácter corporativo de las comunidades étnicas. Las comunidades indígenas suelen ser interpretadas como grupos sociales homogéneos caracterizados por un alto nivel de igualitarismo y solidaridad entre sus miembros.

Al revisar los modelos corporativo cerrado-solidario y el corporativo abierto-individual, la historia de las organizaciones indígenas se caracteriza por una tensión entre ambos. Las condiciones sociales y políticas en un momento histórico de la organización comunitaria, así como la variedad de intereses y situaciones particulares de los comuneros, determinan las tendencias a mantener uno u otro modelo. Las corporaciones cerradas o abiertas, más que modelos explicativos y clasificatorios, corresponden a estadios y etapas por los que suelen atravesar los procesos organizativos indígenas muiscas.

Las categorías de cabildos rurales y cabildos urbanos permiten diferenciar los contextos geográficos y sociopolíticos que han enmarcado la permanencia, emergencia y transformaciones de las comunidades y organizaciones muiscas de Bogotá y Cundinamarca. Sin embargo, las fronteras entre ambas pueden quedar desdibujadas cuando comprendemos que desde una mirada histórica se conectan e identifican mutuamente. Lo que une a los diferentes procesos organizativos muiscas es un proyecto etnopolítico que comenzó con la defensa territorial, sea para comprar un terreno colectivo, o para recuperar predios perdidos generaciones atrás. En la medida en que los relatos fueron avanzando, 
los narradores dieron pistas sobre cómo vinculan sus propias vidas a esos conflictos que forman parte de las memorias colectivas de sus comunidades y se otorgaron un papel en medio de las disputas, luchas y resistencias contadas. La perdurabilidad de la comunidad y de la organización indígenas, por lo tanto, se va a sustentar no solo mediante la relación nominal entre los comuneros y su territorio, sino también en las acciones que estos ponen en práctica para manejar la heterodoxia y la diversidad dentro del colectivo.

Cuando los comuneros vinculan sus historias personales y colectivas con los pasados remotos, identifican a sus comunidades como resultados de largas cadenas de incidencias relacionadas con la manera en que los órdenes territoriales del pueblo muisca fueron transformados por los sistemas colonial y republicano. Con la repartición de sus resguardos en el siglo XIX, las historias de las recientes organizaciones indígenas configuraron sus propios relatos de origen, sus patriarcas y acciones comunitarias que afianzaron la solidaridad resultante de actos individuales mostrados como dignos y casi heroicos.

Sin embargo, una vez impuestos los órdenes territoriales colonial y republicano, los indígenas transitaron diferencialmente por las categorías sociales y raciales que los incluían de una u otra manera en el sistema económico. Con el tiempo se consolidó un campo de tensiones entre quienes vieron la tierra como valor comunitario y colectivo y quienes, en cuanto propietarios, la vieron como mercancía y pasaporte a la vida capitalista. En medio de las tensiones, las corporaciones se fragmentaron mediante acciones individuales que crearon a su vez facciones basadas en alianzas y solidaridades contradictorias.

\section{La identidad muisca está marcada por instancias temporales}

Aunque la conservación de ciertos elementos culturales, sobre todo los relacionados con el territorio, le asignaban el atributo de permanencia espacial a algunas comunidades de herencia muisca en el altiplano cundiboyacense, ser muisca parece ser un estado determinado por instancias temporales; llegar o andar "en lo muisca" o saberlo y asumirlo como denominación de la propia identidad es un asunto transicional. 
El marco político configurado a partir de la Constitución Política de 1991 estableció dos derechos que fortalecieron los procesos de reconocimiento étnico en Colombia y que, por lo tanto, influyeron notoriamente en la consolidación de un campo etnopolítico muisca. El primero fue el derecho a la autodeterminación o autoidentificación, el cual implicó que la conciencia étnica se activara a nivel tanto individual como colectivo en las diferentes comunidades muiscas, las cuales tuvieron que convencerse a sí mismas de su condición étnica o fortalecerla y hacerla más reflexiva y explícita. El segundo derecho fue el de la autonomía, el cual, por el poder que conlleva, significó convencer a las instituciones estatales de la existencia actual del muisca.

Así mismo, los campos conflictivos del autorreconocimiento y de la autonomía revelan una vieja disputa entre dos enfoques o maneras de entender la identidad étnica: el primordialista y el instrumentalista. Tal debate oscila entre la etnicidad en cuanto conjunto de elementos esenciales, prefijados y ligados estrechamente a los lazos emocionales que cohesionan al grupo y la etnicidad en cuanto artefacto socialmente construido, racionalizado y agenciado de manera estratégica para transformar las condiciones políticas del colectivo. La presente investigación asumió el primordialismo y el instrumentalismo no como categorías que caracterizan la totalidad de los procesos etnopolíticos, sino como instancias o momentos que son activados de acuerdo a ciertas circunstancias. Esto le da a la etnicidad un carácter procesual, transicional, liminal y performativo al atravesar ella misma rituales simbólicos y jurídicos en los planos personales, familiares y comunitarios.

La experiencia de los cabildos oficiales nos permite comprender cómo las crisis que motivan la demostración de la condición étnica muchas veces las generan conflictos internos relacionados con el poder, que demuestran que los tránsitos hacia la identidad colectiva no se dan de la misma manera entre sus miembros. La experiencia de PNMC nos hace entender cómo el autorreconocimiento, en cuanto criterio subjetivo para definir la condición étnica, puede resultar agenciado eficientemente. El siguiente caso, que registré mediante trabajo etnográfico y está publicado en Gómez Montañez (2013c), ejemplifica esto último y, además, los conflictos que se producen dentro de la red 
étnica muisca a partir de los esquemas de percepción, pensamiento y acción desplegados.

El 23 de abril del 2012, el líder de PNMC de Bogotá me invitó a un almuerzo que tenía con el alcalde del municipio de Facatativá en un hotel del centro de la ciudad que se llama Hotel Muisca. Alrededor de un puchero santafereño, plato gastronómico típico de Bogotá, la comunidad proyectó un video animado de ficción titulado El último zaque (Yaya, 2011). En concordancia con todos los intentos revisionistas e interpretativos del pasado muisca que hemos visto por parte de este grupo, el video — cuya narrativa está en español e incluye en lengua muisca los diálogos de los personajes indígenas- relata una historia que mezcla datos etnohistóricos con otros más pasionales e imaginativos de carácter moral conexos a dicho pasado. Narra el heroico enfrentamiento de Aquiminzaque, último zaque de Tunja, con los españoles por la defensa de su pueblo. De modo que, de las representaciones del muisca bucólico y contemplativo, pasamos a las del muisca resistente, guerrero y valiente cuyo espíritu no se sometió al blanco, lo que se conecta coherentemente con la red de fenómenos recientes de reivindicación indígena y mesianismo.

El alcalde y parte de su gabinete, como el secretario de gobierno que lo acompañaba, estaban encantados con las palabras de los líderes de esta agrupación objeto de debates. La intención de la comunidad era lograr un convenio marco para que este grupo colaborara en el cuidado y manejo del Parque Arqueológico de Facatativá o Piedras de Tunjo. Incluso, la idea era que a mediano plazo se pudiera proponer ante el Congreso de la República que dicho lugar sagrado se considerara un santuario, así tendría un nuevo manejo especial más afín a lo deseado por los chyquys y sus seguidores. Habían pactado que un sábado próximo a la fecha, el chyquy podía acompañar, a manera de consejero y asesor, una reunión del alcalde con un arquitecto que diseñaría unas construcciones con miras a convertir el parque en un aula arqueológica. El líder de la colectividad tendría la tarea de informar dónde y de qué manera se podrían realizar tales construcciones sin afectar el equilibrio y la energía del territorio. De paso, PNMC explicó su versión sobre el uso de las piedras como plaza de gobierno indígena y la tradición del lugar. La intención era que el alcalde posesionara 
al Cabildo Mayor Muisca de Bacatá, figura de gobierno en Bogotá de esta organización autorreconocida muisca.

Todo parecía indicar que por primera vez este grupo podría posesionar su cabildo ante un ente gubernamental que, aunque no lo certifica oficialmente como parcialidad indígena, es un requisito para lograr dicho estatus ante el Estado colombiano. Pero aunque el papel del alcalde es más simbólico y testifical que de certificador, las dudas sobre este proceso comenzaron a aparecer entre el gabinete. El sábado siguiente al almuerzo tuvimos una actividad académica con mis estudiantes y los abuelos de PNMC en el parque arqueológico. Cuando departíamos una merienda al terminar la actividad, el secretario de gobierno municipal llegó al asadero y charló largamente con el chyquy. Por medio de su teléfono celular, que estaba conectado a Internet, consultaba en todos los documentos jurídicos de acceso público que la ley colombiana sí permitiera la posesión del cabildo. A la semana siguiente, cuando ocurrió el ritual de posesión del cabildo, nadie del gabinete se presentó y la posesión, una vez más, se hizo de manera íntima y simbólica. Los únicos testigos fueron algunos indígenas misaks y algunos tubús hummuri masa. Cuando le pregunté al chyquy por la ausencia del alcalde, me respondió que al parecer se había regado el rumor de la posesión y que el gobernante, para evitar confrontaciones, propuso que la posesión ante él se realizara después a puerta cerrada en su oficina.

La posesión a puerta cerrada nunca se dio, por lo cual, PNMC optó por realizarla de manera ceremonial y simbólica sin incluir ritualidad jurídica administrativa alguna. Un sábado de mayo del 2012, parte de esta comunidad se congregó en el parque arqueológico. El lugar contaba a las tres de la tarde con muy pocos visitantes; la concurrencia más relevante estuvo conformada por un grupo autorreconocido como muisca que a esa misma hora llegaba, la mayoría a pie y algunos de sus líderes en carros. En esos mismos vehículos eran transportados algunos miembros de etnias indígenas colombianas como los misaks del Cauca y los tubús del Vaupés. Frente a un pequeño pantano ubicado unos metros adelante de la entrada del parque, los carros se detenían y varios ocupantes se bajaban y se acercaban a una gran roca 
en cuya base se lograban ver los borrosos índices de antiguos pictogramas de color terracota. Para los abuelos-líderes de PNMC, tal piedra es la guardiana del territorio y es a quien hay que saludar y pedir permiso para ingresar a ese lugar considerado sagrado. La persona saluda apoyando la palma de su mano derecha en la piedra y la izquierda en el pecho sobre el corazón; con los ojos cerrados cada quien le hablaba al elemento guardián.

En el extremo opuesto del parque arqueológico existe una construcción circular en piedra de aproximadamente treinta metros de diámetro. Dicha mole no forma parte de las antiguas piedras y parece un georama que, a manera de escenario, invita a ser usada con el fin de llevar a cabo puestas en escena de todo tipo. A dicho círculo de piedra los líderes de esa comunidad lo denominan la plaza de Gobierno Muisca, y según ellos mismos, era (es) el lugar ordenado por los abuelos ancestrales para ritualizar los actos de posesión de los gobiernos y autoridades indígenas de los pueblos muiscas. La ceremonia comenzó con un repertorio habitual para este tipo de actos de la comunidad, que consiste en el saludo a los espíritus de los "cuatro vientos" (bicha 'tierra', fiva 'viento', gata 'fuego' y sie 'agua'), luego el saludo a los espíritus del cosmos (guacu yeca), a los espíritus del corazón del centro de la tierra (sua tomsa) y al corazón de oro de cada participante (cubni uni).

De modo similar a como es en los cabildos indígenas del suroccidente de Colombia, cada persona con cargo directivo porta un cetro o bastón de poder. El origen de estas prácticas parece ser más una tradición impuesta por los colonizadores españoles que una figura ritual de las etnias indígenas (Rappaport, 2005a). Tales bastones se colocaban sobre el suelo para que la Madre Tierra y los espíritus del territorio de Facatativá - municipio que para esta comunidad se denomina Fa Ata Tiva, vocablo que en lengua renovada muisca significa 'el poder de la primera deidad' - las volvieran a sacralizar. Para llegar a tal significado, $\mathrm{Fa}$ se entiende como "deidad"; Ata es el número uno y Tiva corresponde al cargo de poder que se le otorgaba a un capitán o jefe de un poblado con fuertes vínculos de parentesco. Otras rutinas se integraban a la ceremonia: danzas, toques de tambor y sonajeros 
y cánticos entonados por los miembros de otros grupos étnicos en su respectiva lengua nativa ${ }^{86}$.

A los seis días me encontraba en la Casa Indígena de Cota para coordinar con el gobernador del cabildo de ese territorio la agenda de trabajo para mi investigación doctoral. El gobernador, sin que yo le preguntara, de una vez me comentó que se había enterado de las intenciones de PNMC en el parque arqueológico. Me mostró un ejemplar de una revista de la Fundación Cactus, ONG ambiental que opera en Facatativá, en la que pude ver un pequeño artículo en el que se referían a esta colectividad como "neomuiscas". La foto que ilustraba el escrito era del chyquy, tomada de un fotograma de un video que la misma comunidad alojó en la web (PNMC, 2009) ${ }^{87}$. La intención de los cabildos de Cundinamarca era pronunciarse oficialmente ante las autoridades competentes para evitar que los líderes de este grupo se presentaran como los representantes oficiales de las comunidades muiscas, cuestión que observaban con malestar y sospechas de que fuera un asunto de oportunismos políticos y económicos por parte de sus líderes.

Ese mismo día en la noche visité a una pareja de esposos pertenecientes a PNMC. Dicha pareja fue "empoderada" como guardiana del territorio de Engativá durante una ceremonia posterior a la posesión del cabildo en el parque arqueológico. Al preguntarles su opinión respecto a los rumores y la ausencia del alcalde, el tyba, joven autoridad de la organización, encendió su computador y me reveló el elemento que desencadenó todo. Por las redes sociales un grupo anarquista de Facatativá había puesto en circulación el siguiente panfleto digital ${ }^{88}$ :

86 Para ampliar la información sobre este tipo de rutinas renovadas y puestas en escena relativas a la lengua, el vestuario, la música y la ritualidad, véase Gómez Montañez (2010).

87 En esta producción documental se puede ver al chyquy hablando sobre la ordenanza de las "tres matrices" y la rutina de una limpieza de tabaco en un lugar del Parque Arqueológico de Facatativá.

88 Esta transcripción reproduce fielmente el original. 
Defendamos el parque arqueológico de Facatativá como patrimonio público... NO A LA ENTREGA A PARTICULARES

Rechazamos la presencia y accionar de Nación Muisca (Neoreligión Urbana) en Facatativá

La Nación Muisca, abanderada por los hermanos Niño Rocha, Rodrigo en Tunja y Sigifredo en Bogotá, (Cual Zaque y Zipa), viene dando saltos en lo que denominan reconstrucción Muisca, sin embargo hay referencias preocupantes de esta organización que no son percibidos por la población Facatativeña y menos por los gobernantes de esta ciudad, quienes con afán de fortalecer el sector turístico, están dando puerta abierta a la posesión y reconocimiento legal del Cabildo Mayor muisca de Bacatá y la parcialidad de Facatativa, sin entender las lógicas y desenlaces de dicho acto, programado para el sábado 19 de Mayo.

El parque arqueológico de FACATATIVÁ es patrimonio de la Nación, no debe prestarse, entregarse ni cederse a intereses particulares, por el contrario debe estar abierto a la participación de grupos, organizaciones, etnias sin que prime uno sobre los otros. A la población de Facatativá y a la Administración Municipal: es a este tipo de personas ni nacidos, ni residentes en el municipio a los que buscamos posesionar y reconocer como autoridad, cuando ni la Administración de Bogotá, ni la de Soacha, ni los Cabildos legalmente constituidos los reconocen? Habrá un interés económico al que quiere responder la administración, sin detenerse a ver el contexto que aquí se expone? Qué hay de los nacidos, residentes autóctonos y que desde hace décadas y en silencio han trabajado por la construcción colectiva de la memoria Muisca del territorio?

Organizaciones sociales de la sabana de Bogotá.

El panfleto dio resultado. La administración municipal de Facatativá no posesionó cabildo alguno y las denuncias fueron escuchadas por las comunidades muiscas oficiales. A partir de este caso, se puede comprender que la identidad étnica y la organización indígena son asuntos de tránsitos en los planos burocrático y jurídico estatal, y por ende, 
implican relaciones de poder y agencia en el plano político de las instituciones y dentro de las mismas comunidades indígenas. Meses más tarde Rodrigo, Xieguazinsa, me contó que el panfleto había sido promovido por Tiguasusa, el joven que salió de PNMC después del incidente en el Templo del Sol de Sogamoso ${ }^{89}$. Si Tiguasusa atacaba a los chyquys, resaltando sus tránsitos por el gnosticismo, ahora Rodrigo recordaba el pasado anarquista de Tiguasusa.

Aunque PNMC participa en otros escenarios institucionales para compensar su no certificación como comunidad indígena, aquella vez su objetivo de atravesar un ritual burocrático que los acercara más a la oficialización de su identidad étnica no se logró. Tiguasusa, quien otrora fue miembro de la organización, ahora era uno de sus grandes opositores. Este conflicto y la forma en que se desarrolló en relación con la representatividad étnica para asuntos de un parque arqueológico muestran que los tránsitos que sustentan la etnicidad muisca trascienden el ámbito burocrático, dejando así unas organizaciones en instancias y espacios liminales.

\section{La etnicidad muisca implica una nueva producción de verdad}

Respecto a las comunidades muiscas oficialmente reconocidas por el Estado colombiano, hay que decir que las luchas por la permanencia y defensa de los territorios de resguardo, además del fortalecimiento comunitario y organizativo, conformaron una primera base para la configuración de un campo etnopolítico muisca. Las personas, familias y colectividades descendientes de los muiscas de Cota, Chía, Suba, Bosa y Sesquilé decidieron asumir una identidad étnica bien definida como indígenas, y para ello hurgaron en los usos y costumbres de sus ancestros campesinos para identificar valores y formas de vida que sustentaran una diferencia social y cultural. Al mismo tiempo, atravesaron y fueron atravesadas por rituales de todo tipo para

89 Este episodio lo narro en el apartado "Rodrigo Niño y Orlando Gaitán: disputas por el liderazgo del Zocam" del quinto capítulo. 
transitar hacia el convencimiento y el oficialismo de su identificación étnica. Pero lo cierto es que estas comunidades siempre fueron vistas como sospechosamente construidas, pese a integrar en el gran relato de la historia del pueblo muisca su proceso de organización política y administrativa. A la sociedad mayoritaria le faltaba encontrarse un muisca que realmente pareciera indígena y no campesino o proletario, y las comunidades requerían cada vez más elementos que brindaran un contenido más cercano a lo nativo y primigenio.

En alguna ocasión el mismo joven Tiguasusa me mostró la fotografía de su abuela, campesina de Sogamoso, a quien consideraba su ancestro indígena. Los rasgos faciales, las trenzas de su cabello y la vestidura blanca representaban para su nieto atributos de identidad étnica, y algo similar ocurrió con la fotografía que Sigifredo me mostró de su bisabuela. Tanto Tiguasusa como Sigifredo designan las costumbres y prácticas de cocinar en fogón, cultivar en ciertas fases lunares y el uso de plantas medicinales como elementos indígenas que perduraron en la identidad mestiza de sus ancestros. Por cierto, dentro de PNMC se dispersó un rumor respecto a la muerte de la abuela de Sigifredo y Rodrigo, que se convirtió en una revelación: la señora, agonizando, le dijo a sus nietos: "Mijos, a mí me bautizaron sin mi permiso". Tal frase desplegaba las incidencias que operaron históricamente sobre el pueblo muisca y que transformaron su estructura, sobre todo la religión y la imposición del sistema de parentesco europeo. Otros testimonios recogidos entre integrantes de PNMC coincidían en ese tipo de detalles estructurales con los aportados por comuneros de los cabildos oficiales. Tanto unos como otros se asían de los apellidos, territorios de origen ancestral y ciertas prácticas en cuanto indicadores de indigeneidad; incluso, en una etapa de la escritura de esta investigación, estuve tentado a escribir un capítulo a partir de dichas construcciones narrativas sin especificar la pertenencia o membresía de mis coinvestigadores. La idea era mostrar que las comunidades oficiales y no oficiales elaboran este tipo de anclajes. Sin embargo, algunos miembros desean hacer coincidir las fronteras que separan a quien es y no es muisca con las fronteras establecidas por las resoluciones, oficios y demás documentos jurídicos y administrativos que ritualizan y certifican la pertenencia étnica desde la lógica burocrática del Estado. 
Finalmente, los argumentos de Sigifredo de PNMC y los de Victoria Neuta, de la comunidad de Bosa, respecto a la identidad étnica de sus familias son los mismos, pese a que ambos sean rivales en el campo de poderes de la etnicidad muisca.

Para que la emergencia de ese indígena convincente fuera posible, sus defensores confrontaron la producción de verdad oficial sobre la cultura e historia del muisca y configuraron una propia. Como punto de partida, los muiscas de la actualidad han aceptado su condición mestiza. Como parte de los discursos de reivindicación de su cultura, los muiscas construyen campos de producción de verdad a partir de categorías, conceptos y momentos temporales aparentemente contradictorios. Los oximorones que he propuesto al poner en relación los discursos registrados del mercado de lenguaje muisca y mis propias elaboraciones son: el presentismo del pasado, la alteridad del sí mismo y la mitificación de la historia.

El pasado aparece como un fantasma para recordar la inexistencia o para activar la permanencia. En ambos casos, la identidad indígena suele basarse en construcciones idealizadas del pasado glorioso elaboradas a partir de circunstancias que se actualizan continuamente. Por consiguiente, indigeneizar al campesino o al mestizo conlleva un conjunto de procesos creativos de revisión histórica y de identificación mediante los cuales los muiscas de la actualidad se vinculan moralmente con su pasado, otorgándoles características indígenas a sus ancestros y a su propio estilo de vida con el fin de legitimar y justificar su diferencia cultural. Es un neocriollismo en la medida en que unos grupos de personas han decidido identificarse con quien en otros momentos de su propia historia fue una alteridad oprimida $y$, a la vez, con un hecho del pasado para justificar y legitimar sus luchas en el presente.

Para fortalecer y consolidar una identidad muisca mejor definida y convincente tanto para los mismos indígenas como para la sociedad exterior, y para complementar los procesos organizativos y políticos en torno a la defensa territorial y la perdurabilidad étnica, las comunidades requirieron de un objeto de deseo configurado en la representación del indígena como alteridad idealizada presta para ser incorporada. A medida que las comunidades muiscas de la actualidad escudriñaron el pasado y sus representaciones en búsqueda de referentes ideales 
para indigeneizar a sus ancestros mestizos y a sí mismas, fue apareciendo un nuevo conjunto de prácticas, valores, estéticas y creencias para configurar lo que los muiscas denominan "espiritualidad". Esta dimensión se integró al campo etnopolítico para brindarle un contenido místico y ético a un proyecto de recomposición cultural que a veces parecía quedarse en la absoluta instrumentalización de la etnicidad y en primordialismos poco convincentes para muchos.

Lo muisca podría entonces considerarse como la emergencia y consolidación de un campo estético; no solo surge porque aparecen nuevos rasgos, vestuarios, adornos y rutinas performativas de lo ceremonial y medicinal, también ocurre porque el sensualismo y el narcisismo colectivos propios de esas nuevas performatividades impulsan la conformación de valores morales y de convivencia o ethos. El campo de lo muisca está conformado no por redes de grupos, sino por redes de conformación permanente de grupos. Dos casos lo ejemplifican: los tránsitos y conflictos del joven Tiguasusa, quien luego de separarse de PNMC formó su propia organización llamada Comunidad Tribal Muyska, y la Comunidad Muisca de Ráquira, cuyos líderes provenían de la organización gnóstica y esotérica Fraternidad Universal. Las comunidades a su vez promueven la formación constante de consejos y grupos culturales. Al revisar históricamente la manera como ha sido estudiado el proceso etnopolítico en Bosa, puedo decir que mientras que Durán (2004) abordó a quienes formaban parte del cabildo o de la organización administrativa; y Martínez (2009), a una pareja que en ese momento se referenciaba como sus médicos y chamanes, yo, en mi trabajo de campo, logré tener como una de mis fuentes a un grupo de poporeros e iniciados que se unieron ideológicamente a los mamos de la Sierra Nevada de Santa Marta, y que en ocasiones entran en disputa con la gobernación del cabildo; los acuerdos para unir al pueblo muisca y consolidar su "despertar" parecen descansar, unas veces, en la labor de redes espirituales y, otras veces, en la de líderes políticos. En la historia de la etnicidad muisca han surgido iniciativas de conformación de un cabildo mayor, una consejería y una nación muiscas. 


\section{Conflictos transicionales y la "sobre-espiritualidad" muisca}

Los tránsitos que estructuraron los diferentes procesos de formación de grupos a su vez generaron un flujo constante de ideas, discursos y metodologías que se replicaron, complementaron y actualizaron en cada nodo e instancia de la red étnica. La autoría de tales discursos permitió diferenciar nuevas lecturas y configuró campos de percepciones en los que cada quien defendió su originalidad y validez ante cualquier presunción de estar mimetizado y doblegado con relación a la imagen de otro. Por ejemplo, Sigifredo se refiere a que aquellas personas que fueron parte de PNMC y luego decidieron marcharse y formar otras redes y grupos "se copiaron mal" de él, dice que "se sentaron dos años y formaron rancho aparte con estructura desordenada, sin saber cómo es lo festivo". Además, la conformación de redes de personas cada vez más comprometidas e identificadas con la palabra de los taitas y mamos causó que estas mismas elaboraran y se apropiaran de ethos mediante los cuales juzgaron otras formas de ser muisca hasta tratar de silenciarlas. Trazo un pequeño mapa de esta inconmensurabilidad, como ejemplo.

Heseen Yopasá, usando el nombre de usuario heseeny en el portal web Youtube, hizo comentarios sobre los videos para atacar a Sigifredo (Gómez Montañez, 2010). En una pieza audiovisual en la que se ve al chyquy realizando ofrendas a las piedras sagradas de Facatativá y haciendo limpias de tabaco a personas de su comunidad, Heseen lo califica de "neohippie oportunista". También utiliza el portal para preguntarle por "la plata de los telares y tejidos" con que Sigifredo, supuestamente, se había quedado. Resurgía así el fantasma del pasado de Sigifredo, aquella figura de gestor cultural en Suba que fue cuestionada. La obsesión de Heseen por violentarlo simbólicamente llegó a tal punto que motivó a Sigrifredo a formar un grupo de Facebook denominado Grupo Anti Nación Muisca Chibcha —actualmente ya no existe- Las palabras de Sigifredo evidencian esa pugna entre ellos:

Y lo más contradictorio es que tenemos muiscas metaleros. ¿Qué tiene que ver eso con nuestra cultura, con nuestra cosmogonía o teogonía? Si para nosotros la espiritualidad es otra cosa que 
está alejada de todo ese tipo de conceptos, de modismos o tribus urbanas o formas de expresión donde se cambia el tabaco por la marihuana y la chicha por el aguardiente. (Sigifredo Niño Rocha, 19 de agosto del 2011)

Heseen es un miembro de la comunidad muisca de Suba e integrante de un grupo de rock pesado que fusiona música andina llamado Fushunsua, nombre que una vez escuché que mencionaron los poporeros de Suba y Cota entre risa y burla en un cusmuy mientras raspaban su poporo. Aunque Sigifredo y estos poporeros son partes opuestas de la red de conflictos, coinciden en aplicar un ethos que si bien fundamenta el “despertar” y la recomposición del pueblo muisca en la espiritualidad, termina excluyendo otras formas de expresión e identificación étnicas en la actualidad. Para Heseen Yopasá, los muiscas no buscaron refugio en ningún pueblo hermano, sino en ellos mismos; y su devenir, en medio de la historia y la modernidad. En su versión, así se defiende:

Mucha gente a nosotros nos ha criticado, pero la gente es muy cerrada, es que no entienden para qué carajos uno usa la tecnología. ¿Por qué carajos estudian diseño gráfico? ¿Por qué usan un video? ¿Por qué quieren hacer un juego de video con doblaje muisca? ¿Por qué tienen una banda de rock pesado de metal fusionada con música tradicional y cantan en su idioma al estilo de las bandas de metal? Eso es lo que no cabe en la cabeza de mucha gente, eso es lo que no entienden, que fue básicamente una transformación. Nosotros no desaparecimos, sino nos transformamos, tenemos otra manera de pensar. Nosotros no podemos andar vestidos con el atuendo todo el tiempo, menos con el pelo largo porque no nos dan trabajo, no nos reciben en cualquier parte así, nosotros somos totalmente diferentes, aunque suene extraño a muchos indígenas de este país. (Hessen Yopasá, 6 de noviembre del 2011)

Heseen reclama su propio ethos y observa con sospecha a quienes buscan fundamentar la esencialidad muisca en ceremonias, rituales y atuendos. Líneas más adelante en su testimonio complementaba diciendo que, desde su perspectiva, nadie podía permanecer "en una casita haciendo rituales, sentado en un círculo alrededor de una fogata, 
tomando yagé y entrando supuestamente en trance". Con sarcasmo, Heseen confronta la "palabra bonita", expresión usual de los mamos, diciendo que "entre jóvenes decimos palabras rabonas pero honestas". Respecto a lo "espiritual”, Heseen señala que las culturas indígenas también se basan en otros campos y oficios. De ahí que defienda su trabajo para recuperar la cultura muisca en Suba desde prácticas más cotidianas y más cercanas a las de sus ancestros campesinos, quienes no tuvieron otra opción que adaptarse a los cambios de la ciudad.

Porque lo espiritual es muy complicado, me parece chistoso que hay personas que creen que porque se va a la Sierra Nevada son mamos y todo el mundo anda trabajando lo espiritual. Uno va a la Sierra Nevada y ve arhuacos cultivando la tierra, las mujeres cocinando o tejiendo, haciendo cualquier cantidad de cosas. No con un poporo, y los sabedores espirituales sí están metidos en ese cuento. Eso sería como comparar que como todo el mundo es católico, entonces mañana todo el mundo sale con sotana o todo el mundo con una biblia debajo del brazo. (Hessen Yopasá, 6 de noviembre del 2011)

A pesar de las afirmaciones de Heseen, los líderes de medicina muisca insisten en que la base del "despertar" es "espiritual”. La aplicación de dicho fundamentalismo y la construcción de sus respectivos órdenes morales la he denominado "sobre-espiritualidad de lo muisca". Esta ha propuesto versiones sobre un pasado entre lo histórico y lo mítico tendentes a ubicar en el pasado el inicio de una hermandad y un pacto en el plano espiritual. Cuando la recomposición de la cultura muisca se basa en esta narrativa, parece negar otras condiciones históricas que hicieron posible su existencia, transformación y permanencia. Esa es la razón por la cual Heseen reclama el derecho a reconocer en referentes históricos más cercanos y cotidianos de los comuneros, como la siembra, las labores y hasta la violencia política de los siglos XIX y $\mathrm{xx}$, una memoria muisca de amplio acceso y sin las jerarquías, privilegios simbólicos y requisiciones de un campo de prácticas espirituales conformado por complejas iniciaciones.

Aun así, el trabajo de campo y sus tránsitos hicieron que la investigación se focalizara en un momento en las redes de la espiritualidad 
y la medicina. Desde estos campos los muiscas crearon figuras de lenguaje y discursos para expresar el "despertar", transmitirlo como idea y reflexionarlo como filosofía de vida. Para ello, se identificaron algunos tropos: el recuerdo, el despertar, la curación y el renacimiento; todos conforman un clásico modelo crítico y ritual. Esos momentos críticos, liminales e intermedios de la muerte, el sueño, la enfermedad y el olvido también permiten estratégicamente una aplicación de doble sentido. Los cuatro significan tanto la posibilidad de la desestructuración como la configuración de un sustrato en el que se mantuvo latente el recuerdo, la substancia, el conocimiento y la esencia de la memoria y de la identidad. Por eso, los cuatro tropos transicionales sustentan el "despertar muisca". Tal estado de latencia, más que con el olvido o con una contundente asimilación y mestizaje, se relaciona con una forma de resistencia pasiva. Por eso, el papel de las prácticas medicinales-espirituales ha sido fundamental, pues con estas se accede a la virtualidad, a la ininteligibilidad y a esa ambigüedad que de manera pertinente permite otras construcciones imaginarias, creativas y reivindicadoras no solo del pasado muisca, sino de su continuidad coherente y moral con el presente. Por esta razón, insistimos en que el asunto de la memoria no se limita únicamente a interpretar hechos del pasado, sino también las maneras como dicho pasado - principalmente compuesto de imágenes y eventos fragmentados que de narrativas- se conecta con el presente de quien o quienes lo invocan, y cómo para ello hay que descifrar las incógnitas que quedaron en el momento previo de renacer, despertar, recordar y curar.

Cuando Edward Arévalo Neuta, líder de la comunidad de Bosa, puso su palabra en un círculo de palabra en Usme, donde quiso sintetizar y concretar la metodología que se debía seguir en la resignificación de lugares sagrados, reiteró la manera como hemos propuesto comprender los procesos de recomposición de la memoria e identidad muiscas. En primera medida, se corroboran los tropos de la niñez y el recuerdo y, por lo tanto, la necesidad consecuente de contar con la guía de unos "mayores". Con ello también se fortalecía el tejido de historias míticas sobre el pacto, la devolución de dones y las profecías que nos recuerdan la danza del cóndor y el águila. 
Una característica de nuestra comunidad es que para recobrar, para recordar nuestra tradición hemos tomado una base sólida y firme. Y esa base sólida y firme ha sido o son mayores, ancianos de una tradición. Como lo han dicho los hermanos, se ha repetido, lo muisca no se inventa, se recuerda. Pero se recuerda bajo una base sólida, unas bases tradicionales para así como en este caso que está la institución, pues que eso tenga base. No es una intención ni una percepción personal, sino es una mirada larga de una tradición. Entonces es muy importante que otros mayores que han venido acompañando este despertar, que como sabemos está bajo un gran acuerdo de más de quinientos años, que tienen los bastones, que tienen los canastos de esta tradición, pues que sean ellos los que nos orienten. Porque en el sentido estamos como los niños. Estamos hasta ahora gateando. Pero los pasos no son firmes aún. Hasta ahora estamos despertando. Es muy importante eso, es muy importante conocer la palabra de los ancianos, pero esos ancianos que tienen la base tradicional de la cultura. Para que no se dé paso a crear o a inventar. (Edward Arévalo Neuta, 30 de septiembre del 2012)

Las formas de elaborar la memoria, empleadas por los abuelos o mayores que guían el "despertar muisca", parecen acercarse al misticismo y a esa conexión íntima y personal con el mundo cósmico, energético, y con el de los abuelos espirituales. Porque lo cierto es que, según los sabedores de las comunidades muiscas, el acceso a los secretos del cosmos y a la memoria de la Madre no es una tarea fácil ni permitida a todos. En términos comparativos, las jerarquías que los dogmáticos suelen establecer mediante el acceso a las fuentes escritas y oficiales del conocimiento se reproducen también en las redes místicas, ya que en estas operan metodologías extáticas y de consulta espiritual en las que las plantas sagradas son los puentes entre el mundo humano y el cosmos. Así, pues, hacer memoria desde esta perspectiva implica un ejercicio tanto patológico, porque el recuerdo "aparece" y se manifiesta (mneme), como reflexivo, porque el recuerdo se "busca" (anamnesis). Con ambos tipos de recordación se sustenta el ejercicio de la memoria muisca desde un plano que se ha denominado la "espiritualidad". 
Tal desafío a la oficialidad histórica, es decir, sustentar la memoria muisca en lo incognoscible e indecible, significa que en la medida en que se conforman memorias se producen otras verdades.

\section{Los anclajes y los objetos-red de la memoria}

Las redes y los anclajes de la memoria muisca se dan en relación con memorias simbólicas que construyen imágenes de los pasados posibles y con memorias morales mediante las cuales las personas se vinculan a estos pasados, asumen papeles, son percibidos y fundamentan su "despertar". Para consolidar un cuerpo de valores basados en la interpretación de los asuntos del pasado que cobran vigencia en el presente, se tejen relaciones de intercambio, colaboración y confrontación. El "para qué" de la memoria entonces nos invita a preguntarnos por las acciones concretas que se proyectan en el presente y transforman las condiciones de las comunidades y de sus miembros. A su vez, los muiscas se vinculan al relato de su historia de larga y corta data mediante elementos igualmente compuestos por trayectorias, itinerarios e incidencias.

Hay diferentes itinerarios personales y colectivos que dan sentido a las memorias moral y simbólica muiscas y que conforman redes y cartografías de lo espiritual y lo sagrado. Estos itinerarios, a su vez, pueden clasificarse en dos tipos que se entrecruzan, formando así una trama compleja. Por un lado, aquellos que con base en el orden interno e íntimo de las personas y comunidades otorgan sentidos a ciertos elementos históricos, sociales y culturales de la vida cotidiana y de sus ancestros. Cuando son compuestos a partir de diferentes relatos y fuentes, tales elementos cambian su estatus a medida que los contextos históricos se transforman y son cribados por las motivaciones personales de quienes los integran al campo de la espiritualidad muisca. A estos he propuesto llamarlos "objetos-red de la memoria”. Y por otro, aquellos itinerarios de viajes, ordalías, iniciaciones, pactos y alianzas que conforman redes y asociaciones étnicas. De esta manera, la memoria muisca es configurada ya no solo por un registro remoto, sino también por relatos de la historia reciente que, aunque busca estar vinculada moral y simbólicamente con el pasado, le apuesta a la 
conformación de un campo renovado de héroes y hazañas. A medida que los relatos avanzan se van detectando elaboraciones discursivas y de alto contenido simbólico a través de las cuales sus narradores se vinculan a la trama moral de esas historias. A dichas elaboraciones propongo denominarlas "anclajes", estas le permiten a la persona que las crea vincularse tanto a las narrativas de vieja data como a las más recientes mientras asume papeles, percepciones y juicios de acuerdo a la forma en que las tramas se van narrando y desarrollando.

Los itinerarios personales establecen una compleja red de tránsitos, intercambios e iniciaciones que a su vez conforman nuevas jerarquías, marcos morales, linajes y lealtades. Así se configura un entramado hecho de pioneros que fueron iniciados en el uso de plantas medicinales en viajes o visitas. Las comunidades que paulatinamente fueron integrando prácticas medicinales y espirituales devinieron epicentros y nodos donde sucedieron constantes intercambios; allí los abuelos y mayores de otros pueblos, fieles a las nuevas narrativas, entregaron sus plantas de poder a los muiscas para su "despertar". El tabaco, el ambil, el hayo y el poporo crearon nuevos linajes y constituyeron campos de poder simbólico en donde cada quien es percibido, juzgado y hasta deslegitimado.

\section{Atisbos de resolución de conflictos}

La visión romántica y positiva del intercambio de dones entre pueblos "hermanos", en cuanto fundamento del papel de colaboradores que cumplen otras etnias en el "despertar muisca", contrasta con la dimensión conflictiva determinada por enfrentamientos y oposiciones, es decir, la curación y la solidaridad se manifiestan al tiempo que la enfermedad, la violencia simbólica y la exclusión. Así pues, el intercambio como práctica no siempre conlleva un acuerdo; también provoca o reconfigura conflictos que vivifican aún más estas redes de transacciones. Para el caso muisca, las transacciones corresponden a las iniciaciones en el uso de plantas medicinales, que autoridades espirituales de otros pueblos indígenas brindaron a miembros de diferentes comunidades muiscas - oficiales y no-, y que fueron complementadas o replicadas por parte de líderes muiscas que habían transitado por prácticas 
indígenas foráneas en sus viajes y gracias a sus relaciones personales con chamanaes y taitas.

Con el fin de comprender la manera en que los participantes de estas redes se involucran, interpretan, perciben y actúan en sus redes, desarrollé lo que he denominado "principio histórico-transaccional" y "principio de anclaje”. Ambos principios corresponden a fórmulas discursivas que configuran relaciones legítimas con el pasado y que permiten establecer coherencias con el presente mientras se despliegan y operan esquemas de percepción, pensamiento y acción que hacen del campo etnopolítico muisca un espacio social de poderes simbólicos. Los conflictos se manifiestan en acciones que demuestran que las diferentes facciones no coinciden en sus interpretaciones sobre lo que debe ser el "despertar muisca” y la obligación que ello trae para sus dolientes. Cuando el conflicto escala se llega a niveles de alta inconmensurabilidad. El modo en que se da esta escalada y la aplicación de los dos principios propuestos conforman nuestro modelo analítico de los conflictos etnopolíticos. Con ello reiteramos nuestra premisa de comprender la etnicidad muisca como heterodoxa.

Los órdenes morales que los muiscas han venido construyendo en las redes espirituales a partir de las enseñanzas de las autoridades foráneas no solo han constituido criterios para juzgar y oponerse a otros, también han permitido la puesta en práctica de acciones y rutinas que, basadas también en la lógica del intercambio, intentan darle solución a los conflictos. Janeth Yanguma, abuela de PNMC, fue la protagonista de un evento en el que la trama dio un giro en cuanto a los procesos de inclusión, negociación y acuerdo que se desarrollan en los círculos de palabra muiscas. El hecho ocurrió en medio de un espacio liderado por el taita Orlando Gaitán donde se discutían los conflictos entre los cabildos oficiales y PNMC. La reunión trascurría en una universidad de Bogotá.

Nos encontramos con dos mujeres del cabildo de Bosa a las que yo inocentemente serví chicha y ofrecí y ellas no la recibieron. Fuera de eso me sentí mal. Yo me reúno con todo mi pueblo y ellos han sentido rechazo de algunos personajes cuando dicen "vengo de Pueblo Nación". En base a eso mambeamos con algunas personas 
de la comunidad, no con abuelos, con los nikitivas [miembros varones], las furativas [miembras mujeres] de la comunidad y yo decidí ir. Le dije al taita Orlando que si yo podía ir con él y él me dijo que sí, entonces yo no fui a poner una posición allá política de ninguna índole, únicamente y exclusivamente de amor, de acuerdo, como una madre va hablar de acuerdos por sus hijos. Fui muy bien recibida por el señor gobernador y yo le dije: "Yo no tengo nada en contra suya señor gobernador y espero que si tú tienes algo en contra mía, pues me lo manifiestes y lo podamos curar y sanar desde el aquí y hoy mismo". Me gustó porque el señor gobernador en ese momento me dijo: "No, yo contra sumercé no tengo nada, no hay nada". Que no íbamos a tratarnos así porque nos íbamos a respetar, incluso yo ese día llevé chicha y no la repartí hasta después de que yo hablé y nos dimos un abrazo de fraternidad y de amor. Ahí sí aceptaron la chicha y yo le pedí permiso a él para repartir mi chicha y la repartí. Yo pienso que las cosas frente al pueblo es más que todo por competir, digamos, a nivel de lo que pasó hace quinientos años como hablan las ancianas, es la competencia entre pueblos, como el de poder del pueblo o algo así, que no debería ser así. (Janeth Yanguma, 11 de mayo del 2012)

El testimonio de Janeth Yanguma muestra que es posible aplicar los órdenes morales del "despertar" para llegar a acuerdos. El gesto de las dos mujeres de Bosa de no recibir la chicha fue una señal clara de exclusión y rechazo. Recordemos que la chicha, al igual que otros dones, contiene la esencia y el poder sanador de quien la prepara ${ }^{90}$. Pero lo interesante en este caso es el camino que tomó la abuela; decidió reunirse con los y las jóvenes de su comunidad y no con los líderes. Fue una constante en mi trabajo de campo escuchar que los conflictos entre las diferentes comunidades y organizaciones muiscas solían ser de tipo personal entre autoridades, quienes en su mayoría son hombres. Su perspectiva femenina la motivó a dialogar desde una figura que alimenta la filosofía del "pensar y sentir bonito" y que ella nombra "amor".

90 Me refiero a este atributo de la chicha en el apartado "La fapqua: chichita sagrada" del cuarto capítulo. 
Si bien se estrecharon abrazos, Janeth Yanguma acepta que los conflictos se basan en disputas del pasado por el poder entre las comunidades de su pueblo. Tal vez por eso su esposo Sigifredo continúa siendo juzgado y excluido por otros líderes. En un evento en el cual varias comunidades indígenas se reunieron en Bogotá para escuchar un discurso del presidente Evo Morales, de Bolivia, la gobernadora del Cabildo Muisca de Suba, Claudia Yopasá, agredió verbalmente a Sigifredo y lo atacó refiriéndose a los rumores en torno a los dineros que en el pasado él manejó para gestionar proyectos con esta comunidad.

Aunque los muiscas demandan respeto por su autonomía como pueblo indígena, lo cierto es que su reetnización reciente también muestra que no poseen métodos propios y estructurados de administración de justicia y de resolución de conflictos. En el caso de la comunidad de Suba, me enteré por su exgobernadora, Myriam Martínez Triviño, que el cabildo tomó la custodia de una niña que fue sacada de su casa por sufrir violencia física infligida por su madre. Pero en este caso la medida del cabildo indígena no consistió en impartir una verdadera justicia propia, sino mediar entre la infante con derechos y la institución encargada, el Instituto Colombiano de Bienestar Familiar.

En el cabildo de Bosa, donde además las prácticas espirituales han incursionado con mayor fuerza, su exgobernador Henry Neuta me contó que durante su último año de gestión comenzó un proceso de depuración de miembros de la comunidad. Ante un diagnóstico — similar al de otras comunidades, por cierto- en el que se percibía que la mayoría de los comuneros no se identificaban plenamente como indígenas a menos que eso los beneficiara con mercados, becas y subsidios de salud, Henry y los poporeros convocaron a las familias para reunirse con cada una en el cusmuy de la comunidad. La idea era introducir a los comuneros cada vez más en las dinámicas medicinales de la casa sagrada con miras a que se comprometieran más con el trabajo comunitario. Además, la medicina basada en el tabaco se convirtió en el común denominador de los métodos de resolución de conflictos. $\mathrm{Me}$ contó, por ejemplo, que a parejas y miembros familiares que se violentaban físicamente el cabildo los obligaba a ir al cusmuy a recibir palabra y medicina. Con ello, al tiempo que se innovaban e implementaban métodos de acuerdo, las personas eran motivadas a identificarse como 
indígenas desde un cuerpo de prácticas más diferencial y que pudiera ser definido como propio.

Sin embargo, el caso de Bosa es reciente y aislado, además que obedece, como tantas otras cuestiones y prácticas muiscas, a instancias temporales y a la manera como sus líderes de turno asumen la identidad étnica y la tratan de canalizar en sus comunidades. Por eso, al igual que las redes de prácticas medicinales y espirituales, los métodos e instituciones de resolución de conflictos no se han consolidado y estructurado como formas propias de agenciar los conflictos muiscas. Aun así, los conflictos que se retroalimentan y reproducen todos los días impulsan a estas redes a seguir explorando ideas, innovando métodos y creando órdenes morales propios basados en construcciones del pasado en el que los ancestros dejaron conocimientos a sus descendientes para ser nuevamente aplicados.

Cuando se entra al temazcal de Sesquilé hay que pronunciar la frase: "Por mí y todas mis relaciones". Mediante el vapor y el sudor se limpia a la persona y a la comunidad. Cuando el techo del temazcal se abre, los vapores deben ir al cielo, convertirse en lluvia y limpiar el territorio.

Cuando las redes de prácticas espirituales muiscas han conformado equipos de trabajo para adelantar proyectos de resignificación de lugares sagrados, aplican metodologías que vinculan la adquisición de conocimiento con la limpieza de las enfermedades de la persona, su familia, su comunidad y el territorio. Por eso, con el fin de recuperar la memoria guardada en los elementos, los recorridos por los territorios comienzan con círculos de palabra donde mediante el ambil la persona "entrega sus propósitos" a los padres creadores. Guiadas por los abuelos, taitas y mamos, las personas buscan "limpiar su linaje", pues al recuperar la memoria deben "curar" los males y enfermedades que por generaciones las familias y comunidades han venido sufriendo. Los mamos a eso lo llaman isakechi. Y así, con la conformación de nuevas redes y grupos, nuevas filosofías y discursos terapéuticos van emergiendo y se consolidan como métodos de resolución de conflictos mediante la sanación de un cuerpo integrado por la persona, su familia, su comunidad y su territorio. 
Cuando los muiscas y otros "hermanos" se reúnen para continuar con el "despertar", dicen los abuelos, el cóndor y el águila vuelven a danzar. Pero más allá de ser una metáfora mesiánica romántica, comuneros como Edward, de cuya boca escuché por primera vez tal leyenda contada por los mamos, la toman como un llamado para que el "despertar muisca" sea una tarea que "beneficie a la humanidad". Cuando a tal explicación y a sus anclajes con un pasado ideal no se les buscan los “porqués”, sino los "para qué", es cuando entendemos que proyectos etnopolíticos como el muisca, a partir de sus creativas y desafiantes formas de consolidar renovadas memorias e identidades, ofrecen maneras alternativas de ser ciudadano y ciudadana, identificándose indígena en medio de las contrariedades o los telones de fondo que la modernidad crea y proponiendo otras maneras de ver el pasado, conectarse coherentemente con este y proyectarse hacia el futuro.

\section{Reflexión final}

Algunos líderes muiscas como Henry Neuta, autoridad de la comunidad de Bosa, han definido el "despertar muisca" como un "trabajo que encanta", un sueño colectivo al que algunas personas desean pertenecer, mientras que otras renuncian al descubrir que detrás de tales romanticismos se esconden grandes obligaciones, sacrificios, obstáculos y frustraciones. Sea para ingresar, o para salir; para ser incluido o excluido, el “despertar muisca” está fundamentado en múltiples crisis y tránsitos.

Por un lado, el "despertar" ha sido definido como el paso del pueblo muisca del centro a las márgenes de la historia del campo etnopolítico en Colombia, para luego regresar nuevamente al centro. Por otro lado, el proyecto etnopolítico es entendido como un conjunto de redes, asociaciones, colaboraciones, lealtades, deslealtades, encuentros y desencuentros en los que múltiples agentes marcan sus propios itinerarios. Por lo tanto, el pluralismo y el multiculturalismo se han replicado dentro de las comunidades muiscas, demostrando así que, lejos de ser homogénea, la etnia muisca es configurada constantemente por la heterodoxia y sus grupos son espacios sociales conflictivos o campos de poderes simbólicos. 
Algunas personas han cuestionado mi trabajo al preguntarse si estudiar los conflictos internos — si es que en verdad se les puede denominar así- del pueblo muisca acaso no los afecta. Pero la realidad es diferente. Los propios muiscas conocen la importancia de aprender cómo manejar sus diferencias y disputas para lograr el sueño de un "despertar" armónico, estable y basado en la unión. Los conflictos permiten ver la variedad de formas de identificarse con el "ser muisca", y el sueño del "despertar muisca" ha logrado movilizar iniciativas y procesos en marcos sociales, culturales y políticos tanto a nivel personal como grupal y, asimismo, con alcances locales y regionales. De la misma manera que hemos abordado la etnicidad, el "despertar muisca" es producto de constantes relaciones y tránsitos y depende de contextos particulares y específicos desde los cuales las personas han logrado transformar sus vidas privadas y públicas positivamente. Por esas mismas razones, tal como las motivaciones que llevaron a un hombre blanco a reconocerse nativo-norteamericano en Pensilvania, formar parte del sueño del "despertar muisca" es un asunto transicional y, por ende, político. 


\section{Referencias}

Abbink, J. (2001). Violence and culture: anthropological and evolutionary. Psychological reflections on inter-group conflict in Southern Ethiopia. En B. Schmidt e I. Schröder (eds.), Anthropology of violence and conflict (pp. 176-196). Londres y Nueva York: Routledge.

Acuña, R. (2000). Occupied America: A history of Chicanos. Nueva York: Longman.

Albó, X. (2002). Bolivia: From indianand campesino leaders to councillors and parliamentary deputies. En R. Sieder (ed.), Multiculturalism in Latin America. Indigenous rights, diversity and democracy (pp. 74-102). Londres: Palgrave Macmillan.

Alonso, A. M. (1994). The politics of space, time and substance: state formation, nationalism and ethnicity. Annual Review of Anthropology, 23, 379-405. Recuperado de http://www.jstor.org/stable/2156019.

Álvarez, S. (2013). Leviatán y sus lobos. Violencia y poder en una comunidad de los Andes colombianos. Bogotá: Universidad Santo Tomás.

Anderson, B. (2007). Comunidades imaginadas. Reflexiones sobre el origen y la difusión del nacionalismo. México: Fondo de Cultura Económica.

Angelini, S. (2009). Identidad colectiva e identidad individual en el proceso de reconstrucción cultural de un grupo de indígenas kankuamos desplazados en Bogotá (tesis de maestría inédita). Universidad de los Andes, Bogotá, Colombia.

Appadurai, A. (1991). Las mercancías y la política del valor (Introducción). En A. Appadurai (ed.), La vida social de las cosas (pp. 17-87). México: Grijalbo.

Arenas, N. (2012). Los "neomuiscas", una tribu que reclama cabildo y tierras. Recuperado de https://www.academia.edu/2025165/Los_neomuiscas_ una_tribu_que_reclama_cabildo_y_tierras (sin publicar).

Arenas, N. (10 de junio de 2012). Los “neomuiscas”, una tribu que reclama cabildo y tierras. El Tiempo. Recuperado de https://www.eltiempo.com/ archivo/documento/CMS-11934957 
Balibar, É. (1991). The nation form. En É. Balibar e I. Wallerstein (eds.), Race, nation, class (pp. 96-100). Londres: Verso.

Barbosa, R. (2011). El orden del todo: Sierra Gonawindwa-Shwndwa un territorio de memorias, tendencias y tensiones en torno al ordenamiento ancestral. Medellín: Iepri, Universidad Nacional de Colombia y La Carreta Editores.

Barth, F. (1976). Los grupos étnicos y sus fronteras. La organización social de las diferencias culturales. México: Fondo de Cultura Económica.

Bateson, G. (2001). Espíritu y naturaleza. Buenos Aires: Amorrortu (original publicado en 1979).

Bauman, Z. (2002). Modernidad Líquida. México, D. F.: Fondo de Cultura Económica.

Bazurco, M. (2006). Yo soy más indio que tú. Resignificando la etnicidad. Quito: Abya Yala.

Beck, S. y Mijeski, K. (2000). Indigena self-identity in Ecuador and the rejection of mestizaje. Latin American Research Review, 35(1), 119-137.

Bell, D. (1996). Ethnicity and social change. En J. Hutchinson y A. Smith (eds.), Ethnicity (pp. 138-146). Oxford: Oxford University Press.

Benedict, R. (1967). El hombre y la cultura. Buenos Aires: Sudamericana.

Bhabha, H. (2007). El lugar de la cultura. Buenos Aires: Manantial.

Blimes, R. (2006). The indirect effect of ethnic heterogeneity on the likelihood of civil war onset. The Journal of Conflict Resolution, 50(4) (august), 536-547. Recuperado de http://www.jstor.org/stable/27638505

Boas, F. (1920). The social organization of the kwakiutl. American Anthropologist, 22, 111-116.

Botero, C. (2006). El redescubrimiento del pasado prehispánico de Colombia: viajeros, arqueólogos y coleccionistas, 1820-1945. Bogotá: Instituto Colombiano de Antropología e Historia (Icanh) y Universidad de los Andes.

Boud, M., Koonings, K., Oostindie, G., Ouweneel, A. y Silva, P. (1996). Etnicidad como estrategia en América Latina y el Caribe. Quito: Abya-Yala.

Bourdieu, P. (1989). Social space and symbolic power. Sociological Theory, 7(1), 14-25.

Bourdieu, P. (1991). Language and symbolic power. Cambridge: Polity Press.

Bourdieu, P. y Wacquant, L. (1995). Respuestas por una antropología reflexiva. México: Grijalbo. 
Brass, P. (1990). The politics of India since Independence. New Cambridge History of India, 4(1), 129-134.

Brown, D. ([1970] 2007). Bury my heart at wounded knee. An indian history of the American West. Nueva York: Picador.

Brown, M. (1997). Causes and implications of ethnic conflict. En M. Guibernau y J. Rex (eds.), The ethnicity reader. Nationalism, multiculturalism and migration (pp. 80-100). Cambridge: Polity Press.

Cabildo Indígena Muisca de Suba (1999). Muisca. Un pueblo en reconstrucción. Bogotá: Alcaldía Menor de Suba.

Candau, J. (2006). Antropología de la memoria. Buenos Aires: Nueva Visión.

Cárdenas, F. (2002a). Indios, curas e imaginarios campesinos. En F. Cárdenas Támara, Antropología y ambiente. Enfoques para una comprensión de la relación: ecosistema-cultura (pp. 117-129). Bogotá: Pontificia Universidad Javeriana.

Cárdenas, F. (2002b). El paisaje adivinatorio de los kogi. En F. Cárdenas Támara, Antropología y ambiente. Enfoques para una comprensión de la relación: ecosistema-cultura (pp. 61-89). Bogotá: Pontificia Universidad Javeriana.

Carrillo, M. (1997). Los caminos del agua. Tradición oral de los raizales de la sabana de Bogotá (trabajo de grado inédito). Universidad Nacional de Colombia, Bogotá, Colombia.

Castillejo, A. (2000). Poética de lo Otro. Para una antropología de la guerra, la soledad y el exilio interno en Colombia. Bogotá: Colciencias e Instituto Colombiano de Antropología e Historia (Icanh).

Castillo, L. (2007). Etnicidad y nación. El desafío de la diversidad en Colombia. Cali: Universidad del Valle.

Cohen, A. (1996). Ethnicity and politics. En J. Hutchinson y A. Smith (eds.), Ethnicity (pp. 83-84). Oxford: Oxford University Press.

Comunidad Mhuysqa de Sesquilé (2012). Observatorio Mhuysqa. Un espacio para volver al origen. Bogotá: La Silueta.

Connerton, P. (2006). How societies remember. Cambridge: Cambridge University Press.

Correa Correa, J. (2002). El Resguardo Indígena de Fonquetá y Cerca de Piedra. Los muiscas del siglo XXI en Chía. Chía: Gobernación de Cundinamarca y Alcaldía Popular de Chía. Recuperado de http://muiscasdechia.blogspot.com/ 
Correa Rubio, F. (1993). Encrucijadas de Colombia amerindia. Bogotá: Instituto Colombiano de Antropología (Ican) y Colcultura.

Correa Rubio, F. (2004). El sol del poder. Simbología y política entre los muiscas del norte de los Andes. Bogotá: Universidad Nacional de Colombia.

Correa Rubio, F. (2005). El imperio muisca: invención de la historia y la colonialidad del poder. En A. M. Gómez Londoño (ed.), Muiscas: representaciones, cartografías y etnopoliticas de la memoria (pp. 200-226). Bogotá: Pontificia Universidad Javeriana e Instituto Pensar.

Correa Rubio, F. (2011). Desencializando lo indígena. En G. R. Nemogá Soto (ed.), Naciones indígenas en los Estados contemporáneos (pp. 83-111). Bogotá: Universidad Nacional de Colombia.

Cronk, L. (2002). From true Dorobo to Mukogodo Maasai: Contested ethnicity in Kenya. Ethnology, 41(1) (winter), 27-49.

Curry, G. (1981). The disappearance of the resguardos indigenas of Cundinamarca, Colombia, 1800-1863. Nashville: University Microfilms International.

Chagnon, N. (1968). Yanomamo: The fierce people. Nueva York: Rinehart and Winston.

Chirot, D. y Seligman, M. (2002). Ethnopolitical warfare. Causes, consequences, and possible solutions. Washington, D. C.: American Psychological Assosiation.

De la Peña, G. (2002). Social citizenship, ethnic minotiry demands, human rights and neoliberal paradoxes: a case of study in western México. En R. Sieder (ed.), Multiculturalism in Latin America (pp. 129-156). Nueva York: Palgrave MacMillan.

Durán, C. (2004). El Cabildo Muisca de Bosa. El discurso de un nuevo movimiento social, étnico y urbano (trabajo de grado inédito). Universidad de los Andes, Bogotá, Colombia.

Durán, C. (2005). Ser muisca hoy. La identidad muisca como proyecto colectivo de organización política y cultural en la localidad de Bosa. En A. M. Gómez Londoño (ed.), Muiscas. Representaciones, cartografías y etnopolíticas de la memoria (pp. 348-369). Bogotá: Pontificia Universidad Javeriana e Instituto Pensar.

Durkheim, E. (1968). Las formas elementales de la vida religiosa. Buenos Aires: Schapire S.R.L.

Edwards, J. (1997). Symbolic ethnicity and languaje. En J. Hutchinson y A. Smith (eds.), Ethnicity (pp. 227-229). Oxford: Oxford University Press. 
Eliade, M. (1997). Ocultismo, brujería y modas culturales. Barcelona: Paidós. Engle, K. (2010). The elusive promise of indigenous development. Rights, culture, strategy. Durham y Londres: Duke University Press.

Escribano, M. (2000). Cinco mitos de la literatura oral mbuysca o chibcha. Bogotá: Semper.

Espinosa, M. (2009). La civilización montés. La visión india y el trasegar de Manuel Quintín Lame en Colombia. Bogotá: Uniandes y Centro de Estudios Socioculturales e Internacionales (CESO).

Fenton, S. (2003). Etnicity. Cambridge: Polity Press.

Finley, M. (1996). The ancient greeks and their nation. En J. Hutchinson and A. Smith, Ethnicity (pp. 111-116). Oxford: Oxford University Press.

Fiquitiva, J. (2003). Incidencia de la Constitución Política de 1991 en el Resguardo Indígena de Cota. Bogotá: Ministerio de Cultura.

Fundación Hemera (2006). Concepto etnológico sobre la etnicidad de las comunidades de Cota, Chía y Sesquilé que se reivindican muiscas (informe final ejecutivo). Bogotá: Corporación Regional de Cundinamarca.

Gabbert, W. (2001). Social categories, ethnicity and the state in Yucatán, Mexico. Journal of Latin American Studies, 33(3) (august), 459-484.

Galtung, J. (s. f.). Investigación para la paz y conflictos: presente y futuro. Recuperado de http://www.seipaz.org/documentos/2010JohanGaltung.pdf

Gamboa, J. (2005). Los caciques muiscas y la transición al régimen colonial en el altiplano cundiboyacense durante el siglo XVI (1537-1560). En A. M. Gómez Londoño (ed.), Muiscas: representaciones, cartografías y etnopolíticas de la memoria (pp. 54-72). Bogotá: Pontificia Universidad Javeriana e Instituto Pensar.

Gans, H. (1997). Symbolic ethnicity. En J. Hutchinson y A. Smith (eds.), Ethnicity (pp. 138-146). Oxford: Oxford University Press.

Garbett, G. (1970). The analysis of social situations. Man, 5, 214-227.

García Canclini, N. (2005). Culturas híbridas. Estrategias para entrar y salir de la modernidad. México: Grijalbo.

Garduño, G. (2008). La epistemología de la comunicación en Michel Serres. Revista Cinta Moebio, 31, 23-37.

Geertz, C. (1987). La revolución integradora: sentimientos primordiales y política civil en los nuevos estados. En C. Geertz, La interpretación de las culturas (pp. 219-261). México: Gedisa. 
Giles-Vernick, T. (2001). Lives, histories, and sites of recollection. En S. Miescher y D. Cohen (eds.), African words, african voices (pp. -). Bloomington: Indiana University Press.

Girard, R. (1983). La violencia y lo sagrado. Barcelona: Anagrama.

Glazer, N. y Moynihan, D. (1963). Beyond the melting pot. Cambridge: MIT Press.

Gnecco, C. (2007). Pluralismo, objetos y memoria. En B. Osorio Garcés (comp.), Construcción de la memoria indígena. Bogotá: Siglo del Hombre.

Gómez Londoño, A. (2005a). Lo muisca: el diseño de una cartografía de centro. Chigys Mie: el mundo de los muiscas recreado por la condesa alemana Gertrud von Podewils Dürniz. En A. M. Gómez Londoño (ed.). Muiscas: representaciones, cartografías y etnopoliticas de la memoria (pp. 248-296). Bogotá: Pontificia Universidad Javeriana e Instituto Pensar.

Gómez Londoño, A. (2005b). Muiscas. Representaciones, cartografías y etnopoliticas de la memoria. Bogotá: Pontificia Universidad Javeriana e Instituto Pensar.

Gómez Montañez, P. (2009). Los chyquys de la Nación Muisca Chibcha. Ritualidad, re-significación y memoria. Bogotá: Universidad de los Andes y Centro de Estudios Socioculturales e Internacionales (CESO).

Gómez Montañez, P. (2010). Pyquy, Puyquy, Cubum. Pensamiento, corazón y palabra. Muiscas, performances e interculturalidad. Bogotá: Inpahu.

Gómez Montañez, P. (2011a). El abismo de la palabra: una cartografía crítica del encuentro etnográfico. En F. Reyes y P. F. Gómez Montañez (comps.), Comunicación, sociedad y crisis: escenarios e itinerarios transicionales (pp. 45-83). Bogotá: Inpahu.

Gómez Montañez, P. (2011b). Patrimonio y etnopolíticas de la memoria: el pasado como aparato ideológico en la Fiesta del Zocán en el Templo del Sol de Sogamoso. Revista Antípoda, 12 (enero-junio), 165-186.

Gómez Montañez, P. (2012). Culpas y expiaciones en el despertar muisca: una etnografía de un objeto-red de la memoria. En R. García, A. Jiménez y J. Wilches (eds.), Las víctimas: entre la memoria y el olvido (pp. 253-271). Bogotá: Ipazud.

Gómez Montañez, P. (2013a). Chontales, neohippies y guerras oníricas: memoria y conflicto en la re-etnicidad del Pueblo-Nación Muisca Chibcha. En A. Castillejo y F. Reyes (eds.), Violencia, memoria y sociedad: debates y agendas en la Colombia actual (pp. 517-539). Bogotá: Universidad Santo Tomás. 
Gómez Montañez, P. (2013b). Esbozo de una antropología de lo muisca desde una perspectiva del sur: paralelos y tránsitos. Revista Universitas $\mathrm{Hu}$ manistica, 75, 133-153.

Gómez Montañez, P. (2013c). Memoria, patrimonio arqueológico y utopías interculturales: dogma y misticismo en el parque arqueológico Las Piedras del Tunjo, en Facatativá, Colombia. Revista Hallazgos, 19, 79-99.

Gómez Ramos, M. (1998). Los indígenas de la sabana de Bogotá, de ayer a hoy. El caso de los resguardos de Cota y Suba. Bogotá: Pensamiento Crítico.

González de Pérez, M. (1980). Trayectoria de los estudios sobre la lengua chibcha o muisca. Bogotá: Imprenta Patriótica del Instituto Caro y Cuervo.

Goodman, N. (1978). Ways of worlmaking. Indianapolis: Hackett Publishing.

Gros, Ch. (1991). Colombia indígena. Identidad cultural y cambio social. Bogotá: Cerec.

Gros, Ch. (2000). Politicas de la etnicidad: identidad, Estado y modernidad. Bogotá: Instituto Colombiano de Antropología e Historia (Icanh).

Grosby, S. (1994). The verdict of history: The inexpungeable tie of primordiality -a response to Eller and Coughlan. Ethnic and Racial Studies, 17 (2), 164-171.

Guarín, Ó. (2005). De bárbaros a civilizados: la invención de los muiscas en el siglo XIX. En A. M. Gómez Londoño (ed.), Muiscas: representaciones, cartografías y etnopoliticas de la memoria (pp. 228-246). Bogotá: Pontificia Universidad Javeriana e Instituto Pensar.

Guarín, Ó. (2010). La civilización chibcha y la construcción de la nación neogranadina. Revista Universitas Humanística (70), 205-222.

Guibernau, M. (1997). Nations without States: Catalonia, a case study. En M. Guibernau y J. Rex (eds.), The ethnicity reader. Nationalism, multiculturalism and migration (pp. 133-153). Cambridge: Polity Press.

Gupta, A. y Ferguson, J. (1997). Discipline and practice: “The Field” as site, mood, and location anthropology (pp. 419-451). En A. Gupta y J. Ferguson (eds.), Anthropological locations: Boundaries and grounds of field science. Berkeley: University of California Press.

Halbmayer, E. (2001). Socio-cosmological contexts and forms of violence. War, vendetta, duels and suicide among the yukpa of north-western Venezuela. En B. Schmidt e I. Schröder (eds.), Anthropology of violence and conflict (pp. 49-75). Londres y Nueva York: Routledge.

Halbwachs, M. (2004). Los marcos sociales de la memoria. Barcelona: Anthropos. 
Hall, S. (1996). Diasporic questions. Race, Ethnicity and Identity. En D. Morley y Ch. Kuan-Hsing (eds.), Stuart Hall. Critical dialogues in cultural studies. Londres: Routledge.

Hall, T., Bartalos, Ch., Mannebach, E. y Perkovitz, T. (1996). Varieties of ethnic conflict in global pPerspective: A review essay. Social Science Quaterly, 77(2) (june), 445-452.

Harris, M. (2003). Vacas, cerdos, guerras y brujas. Madrid: Alianza.

Hechter, M. (1986). A racional choice approach to race and etnhic relations. En D. Mason y J. Rex (eds.), Theories of race and ethnic relations (pp. 268-277). Cambridge: Cambridge University Press.

Herrera, M. (2005). Muiscas y cristianos: del biobote a la misa y el tránsito hacia una sociedad individualista. En A. M. Gómez Londoño (ed.), Muiscas: representaciones, cartografías y etnopoliticas de la memoria (pp. 152-179). Bogotá: Pontificia Universidad Javeriana e Instituto Pensar.

Herrera, M. (2007). Ordenar para controlar. Ordenamiento espacial y control político en las llanuras del Caribe y en los Andes centrales neogranadinos. Siglo XVIII. Medellín: La Carreta Histórica.

Hewstone, M. y Cairns, E. (2002). Social psychology and intergroup conflict. En D. Chirot y M. Seligman (eds.), Ethnopolitical warfare. Causes, consequences, and possible solutions (pp. 319-342). Washington, D. C.: American Psychological Association.

Hobsbawm, E. y Ranger, T. (2008). The invention of tradition. Nueva York: Cambridge University Press.

Hoffmann, O. y Agudelo, C. (1998). Políticas agrarias, reformas del Estado y afiliaciones identitarias: una comparación entre Colombia y México. Revista Mexicana de Sociología, 60(4) (octubre - diciembre), 99-123.

Horowitz, D. (1985). Ethnic groups and conflict. Berkeley y Los Angeles: University of California Press.

Hubert, H. y Mauss, M. (1970). De la naturaleza y de la función del sacrificio. En H. Hubert y M. Mauss (eds.), Lo sagrado y lo profano (pp. 29-138). Barcelona: Barral.

Hutchinson, J. y Smith, A. (1996). Ethnicity. Oxford: Oxford University Press.

James, A. y Jiménez, D. (2004). Chamanismo. El otro hombre, la otra selva, el otro mundo. Bogotá: Instituto Colombiano de Antropología e Historia (Icanh). 
Jowitt, K. (2002). Ethnicity: nice, nasty, and nihilistic. En D. Chirot y M. Seligman (eds.), Ethnopolitical warfare. Causes, consequences, and possible solutions (pp. 27-36). Washington, D. C.: American Psychological Association.

Jumí, G. (2011). La cuestión nacional y la cuestión indígena. En G. Nemogá Soto (ed.), Naciones indígenas en los Estados contemporáneos (pp. 65-70). Bogotá: Universidad Nacional de Colombia.

Keating, M. (1997). Canada and Quebec: Two nationalisms in the global age. En M. Guibernau y J. Rex (eds.), The ethnicity reader. Nationalism, multiculturalism and migration (pp. 170-185). Cambridge: Polity Press.

Kibria, N. (2000). Race, ethnic options, and ethnic binds: Identity negotiations of second-generation chinese and korean americans. Sociological Perspectives, 43(1), 77-95.

Kiernan, B. (2002). The ethnic element in cambodian genocide. En D. Chirot y M. Seligman (eds.), Ethnopolitical warfare. Causes, consequences, and possible solutions (pp. 83-92). Washington, D. C.: American Psychological Association.

Kloos, P. (2001). A turning point? From civil atruggle to civil war in Sri Lanka. En B. Schmidt e I. Schröder (eds.), Anthropology of violence and conflict (pp. 176-196). Londres y Nueva York: Routledge.

Koonings, K. y Silva, P. (1999). Construcciones étnicas y dinámicas socioculturales en América Latina. Quito: Abya-Yala.

Kopytoff, I. (1991). La biografía cultural de las cosas: la mercantilización como proceso (pp. 89-122). En A. Appadurai (ed.), La vida social de las cosas. México, D. F.: Grijalbo.

Kuper, L. (1997). Plural Societies. En M. Guibernau y J. Rex (eds.), The Ethnicity Reader. Nationalism, Multiculturalism and Migration (pp. 220-228). Cambridge: Polity Press.

Langebaeck, C. (1990). Buscando sacerdotes y encontrando chuques: de la organización religiosa muisca. Revista de Antropología y Arqueología, VI(1), 81-103.

Langebaeck, C. (1992). Los muiscas desde el siglo xx. En D. Lloreda (dir. ed.), Los muiscas: pasos perdidos (pp. 257-275). Bogotá: Fénix de Colombia.

Langebaeck, C. (1996). Noticias de caciques muy mayores. Bogotá: Universidad de los Andes y Universidad de Antioquia. 
Langebaeck, C. (2005a). La élite no siempre piensa lo mismo. En A. M. Gómez Londoño (ed.), Muiscas: representaciones, cartografías y etnopoliticas de la memoria (pp. 180-199). Bogotá: Pontificia Universidad Javeriana e Instituto Pensar.

Langebaeck, C. (2005b). Resistencia indígena y transformaciones ideológicas entre los muisca de los siglos XVI y XVII. En A. M. Gómez Londoño (ed.), Muiscas: representaciones, cartografías y etnopoliticas de la memoria (pp. 24-51). Bogotá: Pontificia Universidad Javeriana e Instituto Pensar.

Langebaeck, C. (2009). Los herederos del pasado. Indígenas y pensamiento criollo en Colombia y Venezuela (tomo I). Bogotá: Uniandes y Centro de Estudios Socioculturales e Internacionales (CESO).

Latour, B. (2008). Reensamblar lo social. Una introducción a la teoría del actor-red. Buenos Aires: Manantial.

Laurent, V. (2005). Comunidades indígenas, espacios politicos y movilización electoral en Colombia, 1990-1998. Motivaciones, campos de acción e impactos. Bogotá: Instituto Colombiano de Antropología e Historia (Icanh) e Instituto Francés de Estudios Andinos (IFEA).

Laurie, N., Andolina, R. y Radcliffe, R. (2002). The excluded "Indigenous"? The implications of multi-ethnic policies for water reform in Bolivia. En R. Sieder (ed.), Multiculturalism in Latin America. Indigenous rights, diversity and democracy (pp. 252-276). Londres: Palgrave Macmillan.

Lindgren, B. (2004). The internal dynamics of ethnicity: Clan names, origins and castes in Southern Zimbabwe. Journal of the International African Institute, 74(2), 173-193.

Lipovetsky, G. (2002). La era del vacío. Barcelona: Anagrama.

López, M. (2005). Los resguardos muiscas y raizales de la sabana de Bogotá: espacios sociales de construcción de la memoria. En A. M. Gómez Londoño (comp.), Muiscas: representaciones, cartografías y etnopoliticas de la memoria (pp. 332-346). Bogotá: Pontificia Universidad Javeriana e Instituto Pensar.

Llano, M. y Campuzano, M. (1994). La chicha. Una bebida fermentada a través de la historia. Bogotá: Instituto Colombiano de Antropología (Ican) y Centro de Estudios Socioculturales e Internacionales (CESO).

Lleras, R. (2000). La orfebrería y los cacicazgos muiscas. Los problemas del material arqueológico y las etnias. Sabana de Bogotá. En B. Enciso y M. Therrien (comps.), Sociedades complejas en la sabana de Bogotá, siglos VIII al XVI d. C. (pp. 78-93). Bogotá: Instituto Colombiano de Antropología e Historia (Icanh). 
Lleras, R. (2005). Sacrificio y ofrenda entre los muiscas. Revista Travaux de L'IFEA, 79, 43-73.

Maffesoli, M. (2007). En el crisol de las apariencias. Madrid: Siglo XXI.

Marinas, J. M. y Santamaría, C. (1993). La historia oral: métodos y experiencias. Madrid: Debate.

Martínez, S. (2009). Poderes de la mimesis. Identidad y curación en la comunidad indígena muisca de Bosa. Bogotá: Uniandes y Centro de Estudios Socioculturales e Internacionales (CESO).

Mauss, M. (1971). Ensayo sobre los dones: razón y forma del cambio en las sociedades primitivas (pp. 67-259). En M. Mauss, Sociología y antropología. Madrid: Tecnos (original publicado en 1923).

McCauley, C. (2002). The psychology of group identification and the power of ethnic nationalism. En D. Chirot y M. Seligman (eds.), Ethnopolitical warfare. Causes, consequences, and possible solutions (pp. 343-362). Washington, D. C.: American Psychological Association.

McCormick, J. y Alexander, W. (1997). Scotland: towards devolution. En M. Guibernau y J. Rex (eds.), The ethnicity reader. Nationalism, multiculturalism and migration (pp. 154-169). Cambridge: Polity Press.

McFate, M. (2005). Anthropologist and counterinsurgency: The strange story of their curious relationship. Military Review (march-april), 24-38. Recuperado de http://www.au.af.mil/au/awc/awcgate/milreview/mcfate.pdf

Medina de Pacheco, M. (2006). Los muiscas. Verdes labranzas, tunjos de oro, subyugación y olvido. Tunja: Academia Boyacense de Historia y Fondo Mixto de Cultura de Boyacá.

Mitszval, B. (2005). Theories of social remembering. Berkshire: Mc Graw Hill.

Montaña, V. y Cabildo Muisca de Sesquilé (2008). El pueblo de indios de Sesquilé. Bogotá: Villegas Editores.

Morales, P. (2002). La fiesta de Corpus Christi en Atánquez: narrativas múltiples en las intersecciones de la memoria oficial. Bogotá: Uniandes y Centro de Estudios Socioculturales e Internacionales (CESO).

Muelas, L. (2011). La Constitución Política de 1991 y los pueblos indígenas de Colombia. En G. Nemogá Soto (ed.), Naciones indígenas en los Estados contemporáneos (pp. 37-47). Bogotá: Universidad Nacional del Colombia.

Neeman, R. (1994). Invented ethnicity as collective and personal text: an association of rumanian israelis. Anthropological Quarterly, 67(3), 135-149. 
Nemogá, G. (2011) (ed.). Naciones indígenas en los Estados contemporáneos. Bogotá: Universidad Nacional de Colombia.

Nordstrom, C. y Martin, J. (1992). The paths to domination, resistance and terror. Berkeley: University of California Press.

Nugent, D. (2006). Social science knowledge and military intelligence: Global conflict, territorial control and the birth of area studies turing WWII. Journal of World Anthropology Network, 1(3), 31-58.

Nutini, H. (1997). Class and ethnicity in Mexico: Somatic and racial considerations. Ethnology, 36(3) (summer), 227-238.

O’Leary, B. (2002). Nationalism and ethnicity: Research agendas on theories of their sources and their regulation. En D. Chirot y M. Seligman (eds.), Ethnopolitical warfare. Causes, consequences, and possible solutions (pp. 37-48). Washington, D. C.: American Psychological Association.

Oberschall, A. (2002). From ethnic cooperation to violence and war in Yugoslavia. En D. Chirot y M. Seligman (eds.), Ethnopolitical warfare. Causes, consequences, and possible solutions (pp. 119-150). Washington, D. C.: American Psychological Association.

Pearce, W. y Littlejohn, S. (1997). Moral conflict. When social worlds collide. Londres: SAGE.

Pérez de Barradas, J. (1952). Estado actual de los estudios etnológicos sobre los muiscas del Reino de Nueva Granada (Colombia). Madrid: Instituto Gonzalo Fernández de Oviedo.

Pineda, R. (1987). Witoto. En Instituto Colombiano de Antropología, Introducción a la Colombia amerindia (pp. 166-183). Bogotá: Ministerio de Educación Nacional, Instituto Nacional de Cultura e Instituto Colombiano de Antropología (Ican). Recuperado de http://babel.banrepcultural.org/cdm/singleitem/collection/p17054coll10/id/2811/rec/4

Pinzón, C. y Garay, G. (1991). Por los senderos de la construcción de la verdad y la memoria. Hipótesis sobre los procesos de conocimiento en la Amazonia. En C. Pinzón y R. Suárez (ed. y comp.), Otra América en construcción. Medicinas tradicionales y religiones populares (pp. 201-245). Bogotá: Instituto Colombiano de Antropología (Ican).

Pizarro, M. (2005). Chicanas and chicanos in school: Racial profiling, identity battles, and empowerment. Austin: University of Texas Press.

Plant, R. (2002). Latin America's multiculturalism: Economic and agrarian dimensions. En R. Sieder (ed.), Multiculturalism in Latin America. Indigenous rights, diversity and democracy (pp. 208-226). Londres: Palgrave Macmillan. 
Prunier, G. (2002). Genocide in Rwanda. En D. Chirot y M. Seligman (eds.), Ethnopolitical warfare. Causes, consequences, and possible solutions (pp. 109-116). Washington, D. C.: American Psychological Association.

Pueblo Nación Muisca Chibcha - PNMC [Nacionmuiscachibcha] (2009, junio 11). Muiscas - limpia de tabaco en Fa Ata Tiva [archivo de video]. Recuperado de http://www.youtube.com/watch?v=ZFA_lbY2zsA

Rappaport, J. (2000). The politics of memory. A native historical interpretation in the colombian Andes. Cambridge: Cambridge University Press.

Rappaport, J. (2005a). Cumbe renaciente. Una historia etnográfica andina. Bogotá: Instituto Colombiano de Antropología e Historia (Ican).

Rappaport, J. (2005b). Intercultural utopias. Public intellectuals, cultural experimentation, and ethnic pluralism in Colombia. Durham y Londres: Duke University Press.

Rëichel-Dolmatoff, G. (1950). Los kogi. Una tribu de la Sierra Nevada. Bogotá: FEN.

Rëichel-Dolmatoff, G. (1982). La Sierra Nevada: cambio cultural y conciencia ambiental. Revista Colombiana de Antropología, 1(1), 16-122.

Rëichel-Dolmatoff, G. (1991). Los ika. Sierra Nevada de Santa Marta. Notas etnográficas 1946-1966. Bogotá: Universidad Nacional de Colombia.

Rëichel-Dolmatoff, G. (1998). Colombia Indígena. Bogotá: Colina.

Restrepo, L. (2005). Reflexiones sobre los estudios muiscas y las etnopolíticas de la memoria. En A. M. Gómez Londoño (ed.), Muiscas: representaciones, cartografías y etnopoliticas de la memoria (pp. 316-330). Bogotá: Pontificia Universidad Javeriana e Instituto Pensar.

Revista Semana (noviembre, 1993). El último chibcha, Semana. Recuperado de https:/www.semana.com/nacion/articulo/el-ultimo-chibcha/21154-3

Rex, J. (1997). The nature of ethnicity in the proyect of migration. En M. Guibernau, M. Montserrat y J. Rex (eds.), The ethnicity reader. Nationalism, multiculturalism and migration (pp. 269-282). Cambridge: Polity Press.

Rico, L. (2010, enero 18). Pedro Gómez vs. los muiscas: la disputa por la tierra en Suba. La Silla Vacía. Recuperado de http://lasillavacia.com/ historia/5646

Ricoeur, P. (2000). La historia, la memoria, el olvido. Buenos Aires: Fondo de Cultura Económica.

Rocha, M. (2004). El héroe de nuestra imagen. Visión del héroe en las literaturas indígenas de América. Bogotá: Convenio Andrés Bello y Universidad de los Andes. 
Rozo, J. (1999). Resistencias y silencios. Cultura, identidad y sincretismo en los Andes orientales. Bogotá: Icfes.

Sánchez, L. (2004). "La ciudad de paisanos": la construcción de la identidad étnica indígena en Bogotá a partir de un caso de migración (tesis de maestría inédita). Universidad de los Andes, Bogotá, Colombia.

Santos, R. y Mejía, F. (2010). Mensajes de la Madre Tierra en territorio muisca. Bogotá: TierraunA-Cerai.

Santos, R., Mejía, F. y Candil, C. (2012). Observatorio Mhuysqa. Un espacio para volver al origen. Bogotá: Comunidad Indígena Mhuysqa de Sesquilé y La Silueta.

Sarlo, B. (2006). Tiempo pasado. Cultura de la memoria y giro subjetivo. Buenos Aires: Siglo XXI.

Sarrazín, J.-P. (2012). New Age en Colombia y la búsqueda de la espiritualidad indígena. Revista Colombiana de Antropología, 48(2), 239-262.

Schmidt, B. (2001). Anthropology of violence and conflict. Londres: Routledge.

Schröder, B. y Schmidt, I. (2001). Violent imaginaries and violent practices. En B. Schmidt e I. Schröder (eds.), Anthropology of violence and conflict (pp. 1-24). Londres y Nueva York: Routledge.

Schwandner-Sievers, S. (2001). The enacment of "tradition": Albanian constructions of identity, violence and power. En B. Schmidt e I. Schröder (eds.), Anthropology of violence and conflict (pp. 97-120). Londres y Nueva York: Routledge.

Serres, M. (1994). Atlas. Madrid: Cátedra.

Sieder, R. (2002). Multiculturalism in Latin America. Indigenous rights, diversity and Democracy. Londres: Palgrave Macmillan.

Silva, E. (2005). Estudios sobre la cultura chibcha. Tunja: Búhos.

Smith, A. (1996). Culture, community and territory: The politics of ethnicity and nationalism. International Affairs, 72(3), 445-458.

Staub, E. (2002). Ethopolitical and other group violence: Origins and prevention. En D. Chirot y M. Seligman (eds.), Ethnopolitical warfare. Causes, consequences, and possible solutions (pp. 289-304). Washington, D. C.: American Psychological Association.

Stavenhagen, R. (2002). Indigenous people an the State in Latin America: An ongoing debate. En R. Sieder (ed.), Multiculturalism in Latin America. Indigenous rights, diversity and democracy (pp. 24-44). Londres: Palgrave Macmillan. 
Taussig, M. (1993). El diablo y el fetichismo de la mercancía en Suramérica. México: Nueva Imagen.

Taussig, M. (2002). Chamanismo, colonialismo y el hombre salvaje. Un estudio sobre el terror y la curación. Bogotá: Norma.

Taylor, D. (2005). The archive and the repertoire: Performing cultural memory in the Americas. Nueva York: Duke University.

Tibi, B. (1997). Old tribes and imposed nation-states in the Middle East. En J. Hutchinson y A. Smith (eds.), Ethnicity (pp. 174-179). Oxford: Oxford University Press.

Triana, M. (1984). La civilización chibcha. Bogotá: Biblioteca Banco Popular.

Tsutsui, K. (2004). Global civil society and ethnic social movements in the contemporary world. Sociological Forum, 19(1) (march), 63-87.

Tuhiwai-Smith, L. (2004). Decolonizing methodologies. Research and indigenous peoples. Londres y Nueva York: Zed Books.

Turner, V. (1988a). El proceso ritual. Estructura y antiestructura. Madrid: Taurus.

Turner, V. (1988b). The anthropology of performance. Nueva York: PAJ Publications.

Ulloa, A. (2004). La construcción del nativo ecológico. Complejidades, paradojas y dilemas de la relación entre los movimientos indígenas y el ambientalismo en Colombia. Bogotá: Colciencias e Instituto Colombiano de Antropología e Historia (Icanh).

Uricoechea, E. (1992). A la llegada de los conquistadores. En D. Lloreda (dir.), Los muiscas: pasos perdidos (pp. 19-35). Bogotá: Fénix de Colombia.

Urrea, T., del Castillo, J., Cuéllar, J. y Ramos, A. (2011). Usme: historia de un territorio. Bogotá: Alcaldía Mayor de Bogotá, D. C.

Vasco Uribe, L. (1985). Jaibanás. Los verdaderos hombres. Bogotá: Banco Popular.

Vasco Uribe, L. (1988). Derecho, tierra y cultura. Politeia, 1(4) (agosto), 15-20.

Vasco, C. (1990). Tres estilos de trabajo en las ciencias sociales. Comentarios a propósito del artículo "Conocimiento e interés” de Jürgen Habermas. Bogotá: Centro de Investigación y Educación Popular (Cinep).

Villa, S. (2007). El cacique de Turmequé y la ambivalencia del mestizaje. En B. Osorio (comp.), Construcción de la memoria indígena (145-159). Bogotá: Siglo del Hombre y Uniandes. 
Wiesner, L. (1988). Supervivencia de las instituciones muiscas. El resguardo de Cota. Maguaré, 5(5), 235-259.

Wiesner, L. (2000). Etnografía muisca: el resguardo de Cota. En varios autores, Geografía humana de Colombia. Región andina central (tomo IV, vol. II). Bogotá: Instituto Colombiano de Cultura Hispánica. Recuperado de http://www.banrepcultural.org/blaavirtual/geografia/geohum2/ muisca1.htm

Wilmer, F. (1997). First Nations in the USA. En M. Guibernau y J. Rex (eds.), The ethnicity reader. Nationalism, multiculturalism and migration (pp. 186-204). Cambridge: Polity Press.

Wolfson, M. (2004). El chamanismo. Percepción de otros niveles de realidad. Buenos Aires: Longseller.

Yaya, D. [Diego Yaya] (2011, julio 30). El último zaque [archivo de video]. Recuperado de http://www.youtube.com/watch?v=BDdtcYz_ME8

Zambrano, C. (ed.) (1992). Yanacanay en busca del camino real. Etnicidady sociedad en el macizo colombiano. Bogotá: Cabildo Mayor del Pueblo Yanacona, Instituto Colombiano de Antropología (Ican), Colcultura y PNR.

Zambrano, F., Castelblanco, C., Sánchez, L., Hoyos, J. F., Benninghoff, F. y Ruiz, M. (2000). Comunidades y territorios. Reconstrucción histórica de Usaquén. Bogotá: Alcaldía Local de Usaquén.

\section{Entrevistas}

Alfonso Fonseca Balsero, comunero de Cota, 22 de junio del 2012.

Carlos Candil, comunero de Sesquilé, 17 de septiembre del 2012.

Dioselina Triviño Bulla, comunera de Suba, 9 de septiembre del 2011.

Edward Arévalo Neuta, comunero de Bosa, 30 de septiembre del 2012.

Fernando Castillo, comunero de Cota, 12 y 13 de abril del 2012.

Henry Neuta, comunero de Bosa, 24 de agosto del 2012.

Hessen Yopasá, comunero de Suba, 6 de noviembre del 2011.

Janeth Yanguma, comunera de PNMC, 11 de mayo del 2012.

Jhon Orobajo, comunero de Usme, 30 de septiembre del 2012.

Jimmy Fiquitiva, comunero de Cota, 12 y 15 de junio del 2012.

Leonilde Balsero, comunera de Cota, 15 de junio del 2012. 
Luis Calderón, comunero de Cota, 30 de septiembre y 15 de noviembre del 2012.

Myriam Martínez Triviño, comunera de Suba, 9 y 24 de septiembre del 2011. Rodrigo Niño Rocha, líder de PNMC en Boyacá, 18 de diciembre del 2011.

Sigifredo Niño Rocha, líder de PNMC en Bogotá, 19 de agosto del 2011.

Víctor Martínez Taicoma, cacique de la comunidad murui del corregimiento La Chorrera, Amazonas, 12 de marzo del 2013.

Victoria Neuta, comunera de Bosa, 3 de junio del 2012. 



\section{Normatividad y jurisprudencia}

Acuerdo 315 de 2013, por el cual se constituye el Resguardo Indígena Muisca de Fonquetá y Cerca de Piedra, localizado en jurisdicción del municipio de Chía, departamento de Cundinamarca.

Corte Constitucional, Sentencia T-952 de 2010, M. P. Jorge Iván Palacio Palacio.

Corte Constitucional, Sentencia T-792 de 2012, M. P. Luis Ernesto Vargas Silva.

Oficio Csj 015 de la Secretaría Jurídica de Tunja, del 10 de mayo de 2010. 


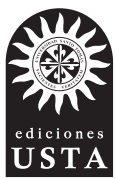

Esta obra se editó en Ediciones USTA.

Se usó papel propalcote de 280 gramos para la carátula y papel bond beige de 75 gramos para páginas internas.

Tipografía de la familia Sabón.

2019 
El llamado "despertar muisca" es un gran proyecto de las actuales comunidades y organizaciones muiscas para que su cultura y sus espacios de representación retornen al centro del campo etnopolítico en Colombia. Su principal desafío es sustentar su existencia como un actor étnico válido. No obstante, aunque podríamos pensar que tal proyecto etnopolítico implica la colaboración entre quienes en la actualidad reclaman la identidad muisca y buscan poner en práctica proyectos de vida comunitaria nuevos y alternativos, lo cierto es que se trata de un espacio social conflictivo por su amplia heterogeneidad.

En consonancia con lo anterior, este libro analiza las fuerzas que concentran y tensionan a la comunidad en el logro de este reconocimiento identitario, al tiempo que conecta el pasado con el presente en el ejercicio de construir memoria y futuro. 